\title{
Prevalence and Predictors of Adverse Childhood Experiences among Youths in Rural communities of Oyo State, South-west, Nigeria
}

Salawu $M M^{1}$, Owoaje ET2

${ }_{1}^{1}$ Department of Epidemiology and Medical Statistics, Faculty of Public Health, College of Medicine, University of Ibadan, Nigeria.

${ }^{2}$ Department of Community Medicine, Faculty of Clinical Sciences, College of Medicine, University of Ibadan, Nigeria.

Keywords
Adverse
childhood
experiences;
Predictors;
Nigeria

\section{ABSTRACT}

Background: Adverse Childhood Experiences (ACEs) are traumatic events a child is exposed to early in life. It is a global problem that constitutes a public health concern. However, few studies have been conducted on ACEs in low- and middle-income countries (LMICs) like Nigeria. This study assessed the prevalence and predictors of ACEs among youths in rural communities in Oyo State, South-west, Nigeria.

Methods: A cross-sectional survey was conducted among 575 youths selected by multistage sampling technique. A structured interviewer-administered questionnaire was used to obtain information on exposure to ACEs; abuse, neglect and household dysfunctions among respondents. Data were analyzed with SPSS version 21.0. Associations were explored with chi-square test and logistics regression analysis. Level of significance was set at $5 \%$.

Results: The mean age (SD) of respondents was 26.3 (4.9) years. Three hundred and forty-two $(59.5 \%)$ respondents were males, $252(43.8 \%)$ had secondary education and 276 $(24.5 \%)$ were classified into the lowest wealth quintiles. Most respondents 529 (92\%) reported they had experienced ACEs. Most prevalent ACEs were psychological neglect 247 (42.9\%), physical neglect 236 (41.0\%), psychological abuse $231(40.2 \%)$ and household substance abuse $223(38.8 \%)$. The predictors of experiencing ACEs were having a mother with primary education and below $(\mathrm{AOR}=2.61 ; \mathrm{CI}=1.383 .51)$ and being in the lowest wealth quintile $(\mathrm{AOR}=1.53 \mathrm{CI}=1.24-2.87)$.

Conclusion: Poor education and poverty contributed to the high occurrence of ACEs among youths in rural south-west. Strategic interventions by government/organizations to improve parental education and ameliorate poverty may be beneficial in reducing ACEs and ensure optimal child development.

Correspondence to: Dr. Mobolaji Modinat Salawu Department of Epidemiology and Medical Statistics, Faculty of Public Health, College of Medicine, University of Ibadan. Email: sannibolaji@yahoo.com Telephone: +234803606 6600

\section{INTRODUCTION}

Adverse Childhood Experiences (ACEs) are defined as potentially traumatic events a child is exposed to in the first 18 years of life that impact negatively on the child's health and wellbeing. ${ }^{1}$ These events are forms of abuse, neglects and household dysfunctions. 
Examples of these forms of events are: physical abuse (push, grab, slap, or throw something at an individual), psychological/ emotional abuse (swear or insult an individual) and sexual abuse (an adult or person at least 5 years older ever touched or fondled an individual in a sexual way); physical neglect (an individual go without important things like clothes, shoes, or school supplies because parents/caregivers spent the money on themselves) and psychological/emotional neglect (an individual ever think his/her parents wished he was never born); household substance abuse (an individual live with anyone who used street drugs or a problem drinker or alcoholic), household mental illness (an individual have a household member who was depressed or mentally ill or attempted suicide), witnessed mother being treated violently (an individual's mother or stepmother pushed, grabbed, slapped, kicked, bitten, hit with a fist or had something thrown at her), parental separation/divorce, (an individual's parents ever separated or divorced) and incarceration of household member (a household member go to prison). ${ }^{1,2}$

Studies have shown that moderate and predictable stress in childhood can lead to the development of mechanisms for coping with life in general, however, severe, repetitive, or chronic stress disturbs normal brain functioning. ${ }^{3}$ Various studies on child maltreatment have shown that ACEs can also result in changes in the brain structure itself and it disrupts early brain development, with long-term impact on the emotional, behavioural and cognitive development of the child.4,5 A global status report by the World Health Organization (WHO) on violence and injury documented that $25-50 \%$ of all children reported being physically abused. ${ }^{6}$ Another form of ACEs is child sexual abuse which is commonly reported globally, with the highest prevalence of $33.4 \%$ in Africa. ${ }^{7}$ A national study conducted in the United States documented that 1 in 7 youths had been exposed to adverse experiences including physical, sexual, and emotional abuse, neglect, and/or family abduction/custodial interference between the ages of 2 and 17 years. ${ }^{8}$ In a national prevalence study of child maltreatment among Romanian families, the prevalence of physical neglect among the adolescents was 46\%. ${ }^{9}$ Research also documented that exposure to household dysfunction such as living with a family member who is an alcoholic, drug addict, mentally ill can be deleterious to the child's wellbeing and future life outcomes. ${ }^{10-}$ 12

One of the few reported studies conducted on ACEs in Nigeria is the National Survey of Mental Health and Wellbeing which documented that $40 \%$ of respondents had been exposed to at least one ACEs occurring within the context of the family by age 16 years. ${ }^{13,14}$ Most of the studies on ACEs have been conducted in developed countries, however, the prevalence and impact of ACEs are higher and more felt in developing countries. ${ }^{15}$ Research in high-income countries has also demonstrated that rural areas have higher rates of childhood poverty 
and a higher probability of ACEs. ${ }^{16}$ This is a public health problem that requires investigation and attention because the burden and impact of ACEs are more pronounced in low- and middle-income countries (LMIC). ${ }^{17,18}$ Therefore, this study assessed the prevalence and predictors of adverse childhood experiences among youths in rural communities of Oyo State, south-west, Nigeria.

\section{METHODOLOGY}

This was a community based crosssectional study which was conducted in five wards of Ibarapa North Local Government Area (LGA) in Oyo State between February and March 2013. The study was conducted in Oyo State, located in South-west Nigeria which was created from the old western region in 1976. There are three senatorial districts in the state (Oyo North, Oyo Central and Oyo South) and 33 LGAs of which 12 are urban, 9 semi-urban and 12 rural. This paper is part of a larger study conducted on ACEs among youths in Oyo State, Nigeria. The study population included youths aged 18-35 years who had been residing in the study area for a minimum of six months. A youth is defined in the National Youth Policy 2009 of the Federal Republic of Nigeria as persons aged $18-35$ years. ${ }^{19}$

The sample size was determined using the Leslie -Kish formula, a prevalence of $56.4 \%$ was used from the study of childhood experiences of adversity among rural South African youths and a total of 575 respondents participated in the study. ${ }^{20,21} \mathrm{~A}$ multistage sampling technique was employed for the selection of study participants. One senatorial district (Oyo South) was selected from the list of the three senatorial districts in Oyo State, Nigeria, by the simple random sampling. One LGA was selected from the list of twelve rural LGAs in the senatorial district by balloting. Thereafter, five wards were selected by balloting from the sampling frame of the wards in the LGA. Four settlements/areas were selected from the list of settlements in the five wards of the selected LGA by balloting. Each settlement/area was taken as a cluster and all consenting youths in each household, in the selected settlements were interviewed.

The questionnaire was adapted from the Adverse Childhood Experiences Questionnaires developed by the Centers for Disease Control and Prevention, USA. ${ }^{22}$ Adverse childhood experiences were determined using the 23 questions that made up the categories of ACEs and household dysfunctions. Information was elicited from the respondents on the following sections:

Section A: Socio-demographic data: This included questions on age, gender, marital status, occupational status and level of education, parental marital status, education, occupation, who respondent lived with first 18 years of life, family wealth assessment and source of income.

Section B: Adverse Childhood Experiences: This assessed the prevalence and pattern of ACEs. Twenty-three questions were used to identify the presence or absence of various 
forms of abuse. Examples of these forms of ACEs are: Psychological/Emotional abuse (swear at, insult, or put an individual down, act in a way that made an individual feel that he/she might be physically hurt); Physical abuse - (push, grab, slap, or throw something at an individual, hit an individual so hard that he/she had marks or were injured); Sexual abuse - (an adult or person at least 5 years older touched or fondled an individual in a sexual way, an adult or person at least 5 years older attempt oral, anal, or vaginal intercourse with an individual, an adult or person at least 5 years older ever actually have oral, anal, or vaginal intercourse with an individual); Physical neglect - (an individual goes hungry or not prepare regular meals, an individual goes without important things like clothes, shoes, or school supplies because parents/caregivers spent the money on themselves, an individual's parents/caregivers ignore or fail to get medical treatment when sick/hurt); Psychological/Emotional neglect - (an individual ever feel loved, an individual ever feel he/she is hated by someone in the family, an individual ever think his/her parents wished he was never born); Household substance abuse - (an individual lived with anyone who used street drugs (marijuana, cocaine), an individual lived with anyone who was a problem drinker or an alcoholic (someone that drinks and he's unable to carryout normal activities); Household mental illness - (an individual had a household member who was depressed or mentally ill, a household member who attempt suicided); Mother being treated violently in the home - (an individual's mother or stepmother pushed, grabbed, slapped or had something thrown at her, an individual's mother or stepmother kicked, bitten, hit with a fist, or hit with something hard, an individual's mother or stepmother ever repeatedly hit over at least a few minutes, an individual's mother or stepmother ever threatened with or hurt by a knife or gun).

Parental separation/divorce - (an individual's parents ever separated or divorced). Incarceration of a household member - examples, a household member goes to prison). Wealth index was derived using the principal component analysis (PCA). A component (wealth index) was extracted after the following variables have been entered into the principal component analysis: possession of land/house, refrigerator, generator, car/motorcycle, television, pipe-borne water. Quintiles of these variables were generated to indicate relative wealth index of the respondents. These were categorized into 1 - lowest wealth quintile/poorest, 2 - second poorest quintile, 3- middle quintile, 4 -fourth quintile and 5 - fifth/top quintile also referred to as the wealthiest quintile. Respondents' age in years was recoded into 18-24 years, 25-30 years, 31-35 years. 19,23 The respondents' and parents' occupations were classified into four categories using the modified socioeconomic classification by British Registrar General's social classes as follows: Professionals/Managerial (doctors, nurses, teachers, lecturers, clergymen, civil 
servants); Skilled non-manual (tailors/ fashion designers, petty traders); Skilled manual (bricklayers, carpenters, plumbers, welders, farmers, mechanics); Unskilled (housewives, students including the unemployed). ${ }^{24}$

Data were collected using an intervieweradministered questionnaire with both open and closed-ended questions. The research instrument was translated to Yoruba, the local language for ease of communication. It was back-translated to English to ensure the original meanings were maintained. The instrument was administered in Yoruba. The copies of questionnaire were administered by four trained research assistants with at least Ordinary National Diploma (OND) qualification. Data collection was done for over eight weeks.

The independent variables were the respondents' and parents' sociodemographic characteristics. The outcome variables were the forms of abuse, neglect and household dysfunctions. Two questions assessed physical abuse, two questions assessed psychological/emotional abuse, three questions assessed sexual abuse, three questions assessed the presence of physical neglect and three questions assessed psychological/emotional neglect. The household dysfunctions were also assessed thus: two questions assessed household substance abuse, two questions assessed household mental illness, four questions assessed witnessing a mother being treated violently, one question assessed incarcerated household member and one question assessed parental separation/ divorce. ${ }^{22}$

These various forms of abuse and neglect experienced in the first 18 years of life were scored. Exposure to abuse or neglect under each category was rated on an ordinal scale; never, rarely, sometimes and often, with the latter two responses scored 1 and classified as exposure to the category, "never" and "rarely" were scored 0 and classified as unexposed to the category. Exposure to household dysfunction was reported with 'yes' (positive) which was scored ' 1 ' and 'no' (negative) response which was scored ' 0 '. The overall prevalence of ACEs was determined using exposure to one or more categories of ACEs.

Data was collated, entered into a computer and analyzed using the IBM Statistical Package for Social Sciences (SPSS) version 21.0. Proportions of youths reporting each of the forms of adverse childhood experiences were derived. Chi-square test was used to test the association between categorical variables (e.g. experience of ACEs and sociodemographic characteristics). Variables significant at $10 \%$ were entered into the binary logistic regression model to identify predictors of ACEs among the respondents. Level of statistical significance was set at $5 \%$. Ethical approval with Protocol Number UI/EC/12/0181 was obtained from the Ethics and Research Committee of the University of Ibadan/ University College Hospital Institutional Review Committee. Permission to conduct the study was also obtained from the Local Government Chairperson. Written informed 
consent was obtained from the respondents after the objectives of the study had been fully explained to them. Respondents' confidentiality and privacy were observed.

\section{RESULTS}

Five hundred and seventy-five youths participated in the survey. Males constituted three hundred and forty-two $(59.5 \%)$ of the population. The mean age (SD) of the respondents was 26.3 (4.87) years and $233(40.5 \%)$ of them were in the age range 18 to 24 years. Four hundred and ninety-one $(85.4 \%)$ of the respondents were of the Yoruba ethnicity. Three hundred and twenty-eight $(57 \%)$ were single/never married, two hundred and fifty-two (43.8\%) had at least a secondary education and two hundred and forty-six (42.8\%) were skilled non-manual by occupation. Table 1. Four hundred and seventy-four (82.4\%) of respondents' parents were married and three hundred and forty-three (72.4\%) were from monogamous homes. Four hundred and fourteen $(72 \%)$ lived with both parents before age 18 years. Only one hundred and ten $(19.1 \%)$ of respondents' mothers had at least a tertiary education. Respondents family wealth index categories were as follows: one hundred and forty-one (24.5\%) respondents were in the lowest/poorest wealth quintile, $131(22.8 \%)$ were in the third/middle quintile and $40(7.0 \%)$ were in the fourth wealth quintile. Table 2.

In Table 3 , the overall prevalence of ACEs among the youths was 529 (92\%). The commonly reported forms of ACEs were; psychological/emotional neglect 247 (42.9\%), physical neglect 236 (41.0\%), emotional abuse 231 (40.2\%), household substance abuse 223 (38.8\%) and physical abuse 210 (36.5\%). Other forms reported were: witnessed violence against their mothers 133 (23.1\%), parental separation or divorce 102 (17.7\%) and sexual abuse 66 (11.5\%). A higher proportion of female respondents 39 (16.7\%) had experienced sexual abuse as compared with the male respondents 27 (7.9\%), ( $\mathrm{p}=0.001)$. A higher proportion of male respondents 174 (50.9\%) had experienced emotional neglect as compared with the female respondents 73 $(31.3 \%), \quad(p<0.001)$. A higher proportion of male respondents $55(20.2 \%)$ had witnessed violence against their mothers as compared with female respondents 47 (16.1\%), $(p=0.042)$ and a higher proportion of males 145 (42.4\%) had witnessed household substance abuse as compared with female respondents 78 (33.5\%), ( $\mathrm{p}=0.031)$.

Table 4 showed an association between respondent's family characteristics and experience of at least one ACEs. Most of the respondents who had experienced ACEs had the following characteristics; lived with single parents/relatives/guardian 156 (96.9\%) as compared with both parents 373 $(90.1 \%)$ before 18 years of life ( $p=0.007)$, had fathers who had primary education and below $267(95.7 \%)$ as compared with fathers who had secondary education and above 


\begin{tabular}{|c|c|}
\hline Variables & n (\%) \\
\hline \multicolumn{2}{|l|}{ Sex } \\
\hline Male & $342(59.5)$ \\
\hline Female & 233 (40.5) \\
\hline \multicolumn{2}{|l|}{ Age (years) } \\
\hline $18-24$ & 233 (40.5) \\
\hline $25-30$ & $218(37.9)$ \\
\hline 31-35 & $24(21.6)$ \\
\hline Mean age \pm SD (years) & $26.3 \pm 4.87$ \\
\hline \multicolumn{2}{|l|}{ Ethnic group } \\
\hline Yoruba & $491(85.4)$ \\
\hline Igbo & $50(8.7)$ \\
\hline Hausa & $29(5.0)$ \\
\hline Igala & $5(0.9)$ \\
\hline \multicolumn{2}{|l|}{ Religion } \\
\hline Christianity & 257 (44.7) \\
\hline Islam & $300(52.2)$ \\
\hline Others & $18(3.1)$ \\
\hline \multicolumn{2}{|l|}{ Marital status } \\
\hline Single & $328(57)$ \\
\hline Married & $240(41.7)$ \\
\hline Divorced/Separated & $7(1.2)$ \\
\hline \multicolumn{2}{|l|}{ Highest level of education } \\
\hline No formal education & $32(5.6)$ \\
\hline Primary education & $88(15.3)$ \\
\hline Secondary education & $252(43.8)$ \\
\hline Tertiary education & 203 (35.3) \\
\hline \multicolumn{2}{|l|}{ Occupation } \\
\hline Unskilled/student/unemployed & $184(32)$ \\
\hline Skilled manual & $81(14.1)$ \\
\hline Skilled non-manual & $246(42.8)$ \\
\hline Professionals/managerial & $64(11.1)$ \\
\hline
\end{tabular}

$\mathbf{n}=\mathbf{5 7 5}$

262 (88.5\%), ( $\mathrm{p}=0.002)$; had mothers who had primary education and below 325 (95.3\%) as compared with mothers who had secondary education $204 \quad(87.2 \%)$, $(\mathrm{p}<0.001)$.

On logistics regression, the predictors of ACEs were as follows; respondents whose mothers had primary education or below were almost three times more likely to had experienced ACEs compared to respondents whose mother had secondary education and above [OR: 2.61 (95\% CI: 1.38-3.51)]. Respondents who lived with single parents in the first 18 years of life were twice more likely to had experienced ACEs compared to respondents who lived with both parents [OR: 2.17 (95\% CI 1.68-4.58)]. In addition, respondents in polygamous homes were more likely to have experienced ACEs compared to those in monogamous homes [OR: 1.00 (95\% CI: 0.415-0.914)]. Also, respondents who were in the lowest wealth quintile were almost twice more likely to have experienced ACEs compared to those who were in the $4^{\text {th }}-5^{\text {th }}$ wealth quintile [OR: 1.53 (95\% CI: 1.24-2.87)] (Table 5). 
Table 2: Sociodemographic characteristics of respondents' family

\begin{tabular}{|c|c|}
\hline Variables & n (\%) \\
\hline \multicolumn{2}{|l|}{ Parents' marital status } \\
\hline Single & $2(0.3)$ \\
\hline Married & $474(82.4)$ \\
\hline Divorced & $28(4.90)$ \\
\hline Separated & $56(9.70)$ \\
\hline Widowed & $15(2.60)$ \\
\hline \multicolumn{2}{|l|}{ Family type $(n=474)$} \\
\hline Monogamous & $343(72.4)$ \\
\hline Polygamous & $131(27.6)$ \\
\hline \multicolumn{2}{|l|}{ No of siblings } \\
\hline$\leq 4$ & $332(57.7)$ \\
\hline$>4$ & $243(42.3)$ \\
\hline \multicolumn{2}{|c|}{ Whom respondent lived with mostly before 18 years } \\
\hline Both parents & $414(72.0)$ \\
\hline Mother only & $55(9.6)$ \\
\hline Father only & $46(8.0)$ \\
\hline Relatives (aunt, uncle, grandparents) & $60(10.4)$ \\
\hline \multicolumn{2}{|c|}{ Parents/guardian average monthly income $(\mathrm{A})$ * } \\
\hline$<18,000$ & $288(50.1)$ \\
\hline$\geq 18,000$ & $287(49.9)$ \\
\hline \multicolumn{2}{|l|}{ Father's level of education } \\
\hline No formal & $146(25.4)$ \\
\hline Primary education & $133(23.1)$ \\
\hline Secondary education & $134(23.3)$ \\
\hline Tertiary & $162(28.2)$ \\
\hline \multicolumn{2}{|l|}{ Mother's level of education } \\
\hline No formal & $177(30.8)$ \\
\hline Primary education & $164(28.5)$ \\
\hline Secondary education & $124(21.6)$ \\
\hline Tertiary & $110(19.1)$ \\
\hline \multicolumn{2}{|l|}{ Wealth index } \\
\hline Lowest & $141(24.5)$ \\
\hline Second & $141(24.5)$ \\
\hline Middle & $131(22.8)$ \\
\hline Fourth & $40(7.0)$ \\
\hline Fifth (highest) & $122(21.2)$ \\
\hline
\end{tabular}

Table 3: Prevalence of Adverse childhood experiences by respondents' sex

\begin{tabular}{|c|c|c|c|c|c|}
\hline *Variables & $\begin{array}{l}\text { Male } \\
\text { n (\%) }\end{array}$ & $\begin{array}{l}\text { Female n } \\
\text { (\%) }\end{array}$ & $\mathbf{X}^{2}$ & p-value & $\begin{array}{l}\text { Total } \\
\text { n (\%) }\end{array}$ \\
\hline Emotional neglect & $174(50.9)$ & $73(31.3)$ & 21.609 & $<0.001$ & $247(42.9)$ \\
\hline Physical neglect & $146(42.7)$ & $90(38.6)$ & 0.946 & 0.331 & $236(41.0)$ \\
\hline Emotional abuse & 134 (41.6) & $97(39.2)$ & 0.346 & 0.556 & $231(40.2)$ \\
\hline Physical abuse & 117 (39.9) & $93(34.2)$ & 1.945 & 0.163 & $210(36.5)$ \\
\hline Sexual abuse & $27(7.9)$ & $39(16.7)$ & 10.667 & 0.001 & $66(11.5)$ \\
\hline Household substance abuse & $145(42.4)$ & $78(33.5)$ & 4.646 & 0.031 & $223(38.8)$ \\
\hline $\begin{array}{l}\text { Witness violence against mother } \\
\text { Parental separation/divorce }\end{array}$ & $69(27.5)$ & $64(20.2)$ & 4.145 & 0.042 & $133(23.1)$ \\
\hline Household mental illness & $55(20.2)$ & $47(16.1)$ & 1.589 & 0.208 & $102(17.7)$ \\
\hline Incarceration of a household member & $\begin{array}{l}15(4.7) \\
8(3.0)\end{array}$ & $\begin{array}{l}11(4.4) \\
7(2.3)\end{array}$ & $\begin{array}{l}0.036 \\
0.241\end{array}$ & $\begin{array}{l}0.849 \\
0.623\end{array}$ & $\begin{array}{l}26(4.5) \\
15(2.6)\end{array}$ \\
\hline Overall prevalence of ACEs & & & & & $529(92.0)$ \\
\hline
\end{tabular}

*Positive responses only were reported in the table. 
Table 4: Association between respondent's family characteristics and experience of ACEs

\begin{tabular}{|c|c|c|c|c|}
\hline \multirow[t]{2}{*}{ Variables } & \multicolumn{2}{|c|}{ ^Experience of ACEs } & \multirow[t]{2}{*}{$\mathbf{X}^{2}$} & \multirow[t]{2}{*}{ p-value } \\
\hline & $\begin{array}{l}\text { Yes } \\
\text { n (\%) }\end{array}$ & $\begin{array}{l}\text { No } \\
\text { n (\%) }\end{array}$ & & \\
\hline \multicolumn{5}{|l|}{ Ethnicity } \\
\hline Yoruba & $447(91.0)$ & $44(9.0) 2$ & & \\
\hline Others (Hausa, Igbo, Igala) & $82(97.6)$ & $(2.4)$ & 4.220 & $0.040 *$ \\
\hline \multicolumn{5}{|l|}{ Family type } \\
\hline Monogamous & $306(89.2) 124$ & $37(10.8) 7$ & & \\
\hline Polygamous & $(94.7)$ & $(5.3)$ & 3.336 & 0.068 \\
\hline \multicolumn{5}{|l|}{$\begin{array}{l}\text { Who respondent lived with before } \\
\text { 18years }\end{array}$} \\
\hline Both parents & $373(90.1)$ & $41(9.9) 5$ & & \\
\hline Single parents/relatives/guardian & $156(96.9)$ & (3.1) & 7.278 & $0.007 *$ \\
\hline \multicolumn{5}{|l|}{ Father's educational status } \\
\hline Primary and below & 267 (95.7) 262 & $12(4.3) 34$ & & \\
\hline Secondary and above & $(88.5)$ & $(11.5)$ & 10.075 & $0.002 *$ \\
\hline \multicolumn{5}{|l|}{ Mother's educational level } \\
\hline Primary and below & 325 (95.3) 204 & $16(4.7) 30$ & & \\
\hline Secondary and above & $(87.2)$ & $(12.8)$ & 12.458 & $<0.001^{*}$ \\
\hline \multicolumn{5}{|l|}{ No of siblings } \\
\hline$\leq 4$ & $299(90.1) 230$ & $33(9.9) 13$ & & \\
\hline$>4$ & $(94.7)$ & (5.3) & 4.016 & $0.045^{*}$ \\
\hline \multicolumn{5}{|l|}{ Wealth index } \\
\hline Lowest wealth quintile & $276(94.7) 117$ & $15(5.3)$ & & \\
\hline Middle quintile & (89.3) & $14(10.7)$ & & \\
\hline $4^{\text {th }}-5^{\text {th }}$ wealth quintile & $145(89.5)$ & $17(10.5)$ & 5.408 & 0.067 \\
\hline
\end{tabular}

*p-value significant; $\wedge$ Experience of at least 1 ACEs

Table 5: Binary logistic regression showing predictors of ACEs in the study population

\begin{tabular}{|c|c|c|c|}
\hline Variables & AOR & $95 \% \mathrm{CI}$ & $\begin{array}{l}\text { p- } \\
\text { value }\end{array}$ \\
\hline \multicolumn{4}{|l|}{ Sex } \\
\hline Male & 0.401 & & \\
\hline Female & 1.000 & $0.312-1.122$ & 0.048 \\
\hline \multicolumn{4}{|l|}{ Ethnicity } \\
\hline Yoruba & 0.419 & & \\
\hline Others (Igbo, Hausa, Igala) & 1.000 & $0.127-0.970$ & 0.060 \\
\hline \multicolumn{4}{|l|}{ Parent's family type } \\
\hline Monogamous & 0.352 & & \\
\hline Polygamous & 1.000 & $0.415-0.914$ & 0.017 \\
\hline \multicolumn{4}{|l|}{ Mother's level of education } \\
\hline Primary and below & 2.612 & & \\
\hline Secondary and above & 1.000 & $1.375-3.514$ & 0.003 \\
\hline \multicolumn{4}{|c|}{ Who respondent lived with before 18 years } \\
\hline Single parent/relatives & 2.169 & & \\
\hline Both parent & 1.000 & $1.675-4.583$ & 0.001 \\
\hline \multicolumn{4}{|l|}{ Wealth quintile } \\
\hline Lowest quintile & 1.534 & & \\
\hline Middle quintile & 1.382 & $1.242-2.866$ & 0.035 \\
\hline $4^{\text {th }}-5^{\text {th }}$ quintile & 1.000 & $0.745-2.472$ & 0.072 \\
\hline
\end{tabular}

\section{DISCUSSION}

This study explored the prevalence and predictors of ACEs among youths in rural communities of Oyo State, south-west, Nigeria. Our results showed that ACEs were prevalent in the study population. The overall prevalence of exposure to at least one category of ACEs in this study was 92\%. This result is similar to a report on Adverse Childhood Experiences survey conducted 
among youths in some developed countries. ${ }^{25-27}$ However, the Nigerian National Survey of Mental Health and Wellbeing documented a lower prevalence of $40 \%$ of ACEs among respondents who were exposed to at least one adverse childhood experience by age 16 years. ${ }^{13}$ This lower prevalence could be because the study reported ACEs in the first sixteen years of life while our study reported ACEs in the first eighteen years of life. Hence, our study captured the full occurrence of ACEs in the first eighteen years of life.

Psychological/Emotional neglect was the most prevalent form of ACEs in the study population. This implies that the youths felt ignored as children and did not receive adequate affection or care.22, 28 The WHO national prevalence study of child maltreatment in Romania, Russia and Latvia documented similar trends. ${ }^{8,29,30}$ This emphasizes the fact that emotional neglect is the commonest form of ACEs which is not visibly seen, often goes unrecognized but often cause harm to the child's developing brain. ${ }^{3,5}$ Physical neglect was experienced by two out of five respondents in our study. There is however a variation in the occurrence of physical neglect in different countries. A national study among youths in Canada and Latvia which are high-income countries documented a lower prevalence of physical abuse. ${ }^{31}$ World Health Organization national study in Romanian, a low- and middle-income country (LMICs) country documented a result similar to our study. ${ }^{32}$ However, similar studies in other LMICs documented a lower prevalence of physical neglect.8, 29 Physical neglect was commonly experienced by the male respondents as compared to the female respondents in this study. This is consistent with findings from a survey on ACEs by Montenegro and Strine et al in a study among the Kaiser Permanente Medical care program in California, a high-income country. ${ }^{31,33}$ However, studies among youths in India and Nepal (LMICs), suggested that girls suffer relatively more physical neglect than boys during childhood. ${ }^{34}$ This could be because some countries as a result of their culture or custom consider the male child as superior to the female child and tend to give better care to the male child as its common in some LMICs. It is important to note that it is difficult to separate poverty from neglect especially in resource-poor countries because of the economic transition. ${ }^{18}$

Psychological/Emotional abuse was reported by $40.2 \%$ of the respondents. A study conducted by the World Studies of Abuse in the Family Environment (World SAFE) among youths in five countries of the world, namely Chile, Egypt, India, Philippines, and the USA documented that Egypt had the highest occurrence of emotional abuse. This is followed by the Philippines, USA and Chile. ${ }^{18,} 35$ Emotional abuse is as damaging as physical and sexual abuse because they put the victim at equal risk of mental and physical health problems. ${ }^{18,36}$ Another commonly reported form of ACEs in this study was physical abuse. According to the WHO, 25 to $50 \%$ of children are physically abused globally. ${ }^{7} \mathrm{~A}$ 
survey of students aged 11 to 18 years in Iran reported exposure to physical violence at home which had caused physical injury ranging from mild to severe. ${ }^{37}$ In addition, our study also showed that more male respondents experienced physical abuse than the female respondents. This is similar to findings from other studies. ${ }^{21,38}$

Sexual abuse was not so commonly reported in this study. However, female respondents had experienced more sexual abuse than male respondents. This finding is consistent with most literature that females are more likely than their male counterparts to report sexual abuse. ${ }^{35,38}$ The UN World Report on Violence Against Children documented that more than 150 million girls and 73 million boys under the age of 18 had experienced forced sexual contact or sexual violence of another physical type. ${ }^{39}$ Gilbert et al in a study of burden and consequences of child maltreatment in high-income countries documented that sexual abuse is experienced by $15-30 \%$ of girls and $5-15 \%$ of boys. ${ }^{27}$ A meta-analysis study by Pereda et al estimated that $7.9 \%$ of men and $19.7 \%$ of women globally experienced sexual abuse before age 18years. The meta-analysis reported that prevalence of sexual abuse in the U.S. was $7.5 \%$ for males and $25.3 \%$ for females; the lowest prevalence rate was found in Europe (9.2\%) and Africa recorded the highest prevalence rate of sexual abuse geographically (33.4\%). ${ }^{7}$ Another study in Tanzania also reported a higher prevalence of sexual abuse among female respondents than the male respondents. 40 Some other studies documented contrary report that males reported more sexual abuse than their female counterpart. ${ }^{33,41}$ This could be that females under-report sexual abuse for fear of being stigmatized, laughed at or even because of the culture of silence in LMICs as well as most part of Africa where the victim cannot talk about her experience for cultural reasons.

Household substance abuse, parental separation/ divorce and witnessing violence against mother were also reported by the respondents. This is similar to a report from other studies. ${ }^{21,29}$ It is estimated that every year 133 to 275 million children worldwide witness violence between their parents/carers frequently, usually fights between parents, or between their mother and her partner.39 Exposing a child to household violence and substance abuse is as harmful as inflicting physical violence on the child which could cause emotional trauma to the growing child.12,39 Respondents who lived with single parents before 18 years of life and had mothers with primary education and below were more likely to have experienced ACEs. These results were similar to reports documented in other studies. ${ }^{14}, 29$ Respondents in polygamous homes were more likely to have experienced ACEs compared to those from monogamous home. Similarly, UNICEF report from Algeria and Gambia documented that violent child discipline is more common in households practising polygamy. ${ }^{38}$ These reports were from African countries which suggest polygamy is mostly practised in African countries. In addition, polygamy is known to be associated with 
hatred, jealousy and rivalry among the wives and children in the polygamous homes. This study also showed that being in the lowest wealth quintile increased the odds of ACEs as compared to those who were in the upper quintile. This corroborated a report by UNICEF that children who come from 50\% poorest household experienced physical and emotional abuses compared to the $40 \%$ from wealthier households. 38 This could be because poverty contributes to pervasive stress at home and in the environment.

Study limitations: The results of this study are subject to some limitations. Firstly, this was a cross-sectional study, hence the temporal sequence of the association between ACEs and the identified predictors cannot be established, but the results are in keeping with other published literature. Another weakness is the possibility of recall bias because of the retrospective reporting of ACEs experienced in the first eighteen years of life, hence there is the possibility of under-reporting or over-reporting the event.

Conclusion: This study showed a high prevalence of ACEs among youths in the rural communities of south-west, Nigeria. Emotional neglect was the most commonly reported form of ACEs while most of the respondents had experienced all forms of ACEs. Poverty and poor education were identified as risk factors for ACEs.

These findings highlight the need for government and organizations to develop strategies to ameliorate poverty and its negative effects among families and children. In addition, interventions should be developed to address parental education and provide support to educate parents about non-violent ways of disciplining children. These will reduce the risk factors for ACEs and provide an enabling environment for optimal child growth and development.

Acknowledgements: We acknowledge the support and assistance of the staff of Ibarapa Local Government Area (LGA) and the community leaders. We appreciate the field staff for their efforts and expertise in the data collection process.

Conflicts of interest: The authors declare no conflict of interest.

Contributions to joint publication: MMS conceived the study, MMS and ETO designed the study. MMS was involved in data collection and analysis of data. MMS and ETO interpreted the data. MMS wrote the first draft of the paper. MMS and ETO were involved in critically revising the manuscript for important intellectual content. All authors read and approved the final manuscript.

\section{REFERENCES}

1. Anda RF, Butchart A, Felitti VJ and Brown DW. Building a framework for global surveillance of the public health implications of adverse childhood experiences. American Journal of Preventive Medicine 2010; 39: 93-98.

2. Anda RF, Felitti VJ, Bremner JD, Walker JD, Whitfield C, Perry BD, et al. The enduring effects of abuse and related adverse experiences in childhood. A 
convergence of evidence from neurobiology and epidemiology. Eur Arch Psychiatry Clin Neurosci 2006; 256: 174-186. 2005/11/29. DOI: $10.1007 / \mathrm{s} 00406-005-0624-4$.

3. Perry B. Examining child maltreatment through a neurodevelopmental lens: clinical applications of the neurosequential model of therapeutics. Trauma and Loss 2009; 4: 240-255.

4. Brown DW, Anda RF, Felitti VJ, Edwards VJ, Malarcher AM, Croft JB, et al. Adverse childhood experiences are associated with the risk of lung cancer: a prospective cohort study. BMC Public Health 2010; 10: 20. DOI: 10.1186/1471-2458-10-20.

5. Leeb RT, Lewis $\mathrm{T}$ and Zolotor AJ. A Review of Physical and Mental Health Consequences of Child Abuse and Neglect and Implications for Practice. 2011; 5: 454-468. DOI: $10.1177 / 1559827611410266$.

6. World Health Organization and the United Nations Office on Drugs and Crime and the United Nations Development Programme. Global status report on violence prevention. Violence and Injury Prevention. 2014, (accessed 12 March 2020). http://www.who.int/violence_injury_pr evention/violence/status_report/2014/ $\underline{\text { en/ }}$

7. Pereda N, Guilera G, Foms $\mathrm{M}$ and Gomez-Benito J. The prevalence of child sexual abuse in the community and student samples: a meta-analysis. J Clinical Psychology Review 2009; 29: 328-338.

8. Finkelhor D, Ormrod R, Turner $\mathrm{H}$ and Hamby SL. The victimization of children and youth: a comprehensive national survey. Child Maltreat 2005; 10: 5-25.

9. Browne KD. National prevalence study of child abuse and neglect in Romanian families. Copenhagen: WHO Regional Office for Europe. 2002, (accessed 20 January 2014). www.euro.who.int $>$ assets $>$ pdf_file
10. Gruber $\mathrm{K}$ and Lcsw M. A Family Perspective for Substance Abuse: Implications from the Literature. Journal of Social Work Practice in the Addictions 2006; 6: 1-29. DOI: 10.1300/J160v06n01_01.

11. Thatcher DL and Clark DB. Adolescents at risk for substance use disorders: role of psychological dysregulation, endophenotypes, and environmental influences. Alcohol Res Health 2008; 31: 168-176.

https://pubmed.ncbi.nlm.nih.gov/2358 $\underline{4818 .}$

12. Douglas KR, Chan G, Gelernter J, Arias AJ, Anton RF, Weiss RD, et al. Adverse childhood events as risk factors for substance dependence: partial mediation by mood and anxiety disorders. Addictive behaviours 2010; 35: 7-13. 2009/09/02. DOI: 10.1016/j.addbeh.2009.07.004.

13. Oladeji BD, Makanjuola VA and Gureje O. Family-related adverse childhood experiences as risk factors for psychiatric disorders in Nigeria. The British Journal of Psychiatry 2010; 196: 186-191.

14. Ige OK, Ilesanmi OS and Adebayo AM. Sexual Risk Behaviours among Young People with Adverse Childhood Experiences in Ibadan, Nigeria. Greener Journal of Medical Sciences June 2012; 2: $70-76$.

15. AlBuhairan FS, Tamim H, Al Dubayee M, AlDhukair S, Shehri S, Tamimi W, et al. Time for an adolescent health surveillance system in Saudi Arabia: findings from 'Jeeluna'. J Adolesc Health 2015; 57: 263-269.

16. National Advisory Committee on Rural Health and Human Services. Rural health and human service issues. 2009, (accessed 10 June 2018) https: / / www.hrsa.gov>rural>publicatio ns.

17. Ismayilova L, Gaveras E, Blum A, TôCamier A and Nanema R. Maltreatment and Mental Health Outcomes among Ultra-Poor Children in Burkina Faso: A Latent Class Analysis. PLoS One 2016; 
11: e0164790-e0164790. DOI: 10.1371/journal.pone.0164790.

18. Ramiro LS, Madrid BJ and Brown DW. Adverse childhood experiences (ACE) and health-risk behaviours among adults in a developing country setting. Child Abuse \& Neglect 2010; 34: 842855.

19. Federal Government of Nigeria. National Youth Policy, Federal Ministry of Youth and Development. 2009, (accessed 16 December

2012). https://www.youthpolicy.org/national/ Nigeria_2009_National_Youth_Policy.pdf

20. Kirkwood BR and Sterne JAC. Essentials of Medical Statistics 2nd Edition. 2nd ed.: Blackwell Scientific Publications, 2003, p.432-433.

21. Jewkes RK, Dunklec K, Ndunad PM, Jamaa $\mathrm{N}$ and Purene A. Associations between childhood adversity and depression, substance abuse and HIV and HSV2 incident infections in rural South African youth. Child Abuse \& Neglect 2010; 34: 833-841.

22. Centres for Disease Control and Prevention. Department of Health and Human Services. Adverse Childhood Experiences Study. 2005, (accessed February 2012)

https://www.cdc.gov/violencepreventio

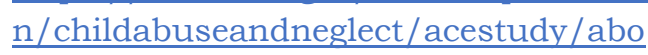
ut.html.

23. National Population Commission (NPC). Nigeria Demographic and Health Survey, Abuja, Nigeria. National Population Commission and ICF Macro. 2008, (accessed March 2012). https://dhsprogram.com/pubs/pdf/FR 293/FR293.pdf.

24. Connelly R, Gayle V and Lambert PS. A Review of occupation-based social classifications for social survey research. 2016; 9: 2059799116638003. DOI: $10.1177 / 2059799116638003$.

25. Feron C. Report on Results of Lake County Survey of Adverse Childhood Experiences. 2010, (accessed 02 February 2012). http://www.firstfivelake.org/resources/
FINAL\%20Adverse\%20Childhood\%20Ex periences $\% 20$ Summary $\% 20$ Report $\% 200$ n\%20Results\%20of\%20Lake\%20County \%20Survey.pdf

26. Soares ALG, Howe LD, Matijasevich A, Wehrmeister FC, Menezes AMB and Goncalves H. Adverse childhood experiences: Prevalence and related factors in adolescents of a Brazilian birth cohort. Child Abuse and Neglect 2016; 51: 21-30.

27. Gilbert R, Widom CS, Browne K, Fergusson D, Webb $\mathrm{E}$ and Janson $\mathrm{S}$. Burden and consequences of child maltreatment in high-income countries. Lancet 2009; 373: 68-81.

28. Ludwig S and Rostain A. (Chapter 10) Family Function and Dysfunction. 2009. In: Carey WB, Crocker AC, Coleman WL, et al. (eds) Developmental-Behavioral Pediatrics (Fourth Edition). Philadelphia: W.B. Saunders, pp.103-118.

29. Velika B, Pudule I, Grinberga D, Springe L and Gobina I. Adverse Childhood Experiences of Young Adults in Latvia. Study Report from the 2011 Survey. Ministry of Health of the Republic of Latvia. Centre for Disease Prevention and Control, Latvia 2011. Accessed May 2014. Available at: http://www.cdc.gov/nccdphp/ace/.

30. World Health Organisation. Survey on the prevalence of adverse childhood experiences among young people in the Russian Federation. 2014, (accessed June 2017). www.euro.who.int $>$ publications

31. Strine TW, Edwards VJ, Dube SR, Wagenfield M, Dhingra S, Prehn AW, et al. The mediating sex-specific effect of psychological distress on the relationship between Adverse childhood experiences and current smoking among adults. Substance abuse, Treatment, Prevention and Policy 2012; 7: 30.

32. Browne KD. National prevalence study of child abuse and neglect in Romanian families. Copenhagen. 2002, (accessed 20 January 2014). www.euro.who.int $>$ assets $>$ pdf_file 
33. World Health Organisation. Survey on Adverse Childhood Experiences in Montenegro. National Survey Report. 2014, (accessed 10 April 2016).

https: //apps.who,int>handle

34. Government of India. India country report on violence against children. New Delhi, Department of women and Child Development, Ministry of Human Resource Development, Government of India. 2005, (accessed August 2019). https: //childlineindia.org. in $>$ pdf $>$ mwc

35. Krug EG, Dahlberg LL, Mercy JA, Zwi AB and Lozano $\mathrm{R}$. World report on violence and health. Geneva, World Health Organization, 2002, (accessed 15 February 2016). https://www.who.int>summary_en

36. Dube SR, Felitti VJ, Dong M, Chapman DP, Giles WH and Anda RF. Childhood abuse, neglect, and household dysfunction and the risk of illicit drug use: the adverse childhood experiences study. Pediatrics 2003; 111: 564-572. 2003/03/04. 10.1542/peds. 111.3 .564 .

37. Sheikhattari P, Stephenson R, Assasi N, Eftekhar H, Zamani Q, Maleki B, et al.
Child maltreatment among school children in Kurdistan Province, Iran. Child Abuse and Neglect 2006; 30.

38. UNICEF. Child Disciplinary Practices at Home: Evidence from a Range of Lowand Middle-Income Countries. 2010, (accessed June 2017). https://violenceagainstchildren.un.org> countries

39. Pinheiro PS. World Report on Violence against Children. Secretary-General's Study of Violence against Children, 2006, (accessed 10 June 2018).

http://www.unicef.org>violencestudy

40. McCranna D, Lalor K and Katabaro JK. Childhood sexual abuse among university students in Tanzania. Child Abuse \& Neglect 2006: 1343-1351.

41. World Health Organisation. Survey of Adverse Childhood Experiences among young people in the former Yugoslav Republic of Macedonia. 2013, (2006, accessed July 2017). www.euro.who.int $>$ publications $>$ survey 